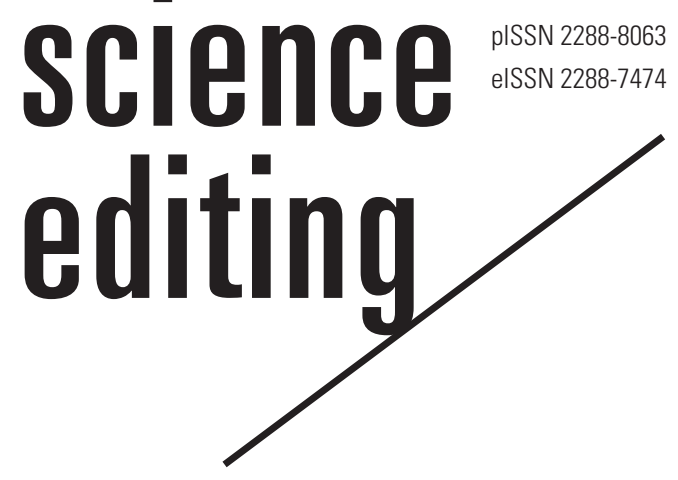

\title{
Changes in bibliographic information associated with Korean scientific journals from 2011 to 2019
}

\author{
Yoon Joo Seo', Hye-Min $\mathrm{Cho}^{2}$, Sun Huh ${ }^{3}$ \\ ${ }^{1}$ Committee of Manuscript Editing, Korean Council of Science Editors, Seoul; ${ }^{2}$ Infolumi, Seongnam; ${ }^{3}$ Department of \\ Parasitology and Institute of Medical Education, College of Medicine, Hallym University, Chuncheon, Korea
}

Abstract

Purpose: This study aimed to examine how the bibliographic information of 558 journals that applied for the Korean Federation of Science and Technology Societies funding in 2011 changed from 2011 to 2019, with the goal of informing the development of Korean scientific journals.

Methods: Between May and October 2012, bibliographic information from 558 journals was obtained from PDF files for the print versions of one issue of 2011 and the journal homepages. In August 2019, the bibliographic information of the same journals was traced based only on the journal websites. We compared bibliographic information.

Results: Excluding 14 journals that were discontinued or integrated with other journals prior to the follow-up in 2019, 544 journals were compared. Over the 8-year period, 121 journals underwent title changes. The number of journals with eISSNs (electronic International Standard Serial Number) increased from 214 (39.3\%) in 2011 to 488 (89.7\%) in 2019. "Aims and scope" descriptions were found for 291 journals (53.5\%) in 2011 and 482 (88.6\%) in 2019. The number of English-only journals increased from 163 (30.0\%) to 227 (41.7\%), and the number of journals with an open access policy rose from 92 (16.9\%) to 315 (57.9\%). Journals with DOI (digital object identifier) prefixes increased from 256 (47.1\%) to $536(98.5 \%)$.

Conclusion: The increased frequency of the above bibliographic information is evidence of the globalization of local journals. However, even in 2019, some journals still lacked the necessary bibliographic information. For better dissemination and promotion of Korean scientific journals, editors and publishers should more critically consider the proper inclusion of information on journal websites.

Keywords

Access to information; Bibliography; Follow-up studies; Periodicals as topic; Republic of Korea

This is an open access article distributed under the terms of the Creative Commons Attribution License (https://creativecommons.org/licenses/by/4.0/) which permits unrestricted use, distribution, and reproduction in any medium, provided the original work is properly cited. 


\section{Introduction}

Background/rationale: Most Korean scientific journals are published by academic societies or nonprofit organizations, including research institutes and public institutions. The Korean Federation of Science and Technology Societies (KOFST) has supported journals and academic conferences since 1971. As such, KOFST routinely receives financial support requests from publishers. The minimum criterion to apply for financial support is indexing in the National Research Foundation of Koreamaintained Korea Citation Index, a literature database in which scholarly journals are indexed after a strict selection process. To be selected for KOFST funding, journals are evaluated for their compliance with the international standards of scholarly journal publishing [1]. Therefore, journal editors must ensure that their journals fit the KOFST selection criteria, which include some required bibliographic information. To this end, it will be helpful to examine the effect of journal evaluations by KOFST in 2011 by tracing changes in bibliographic information over the following 8 years.

Purpose: We aimed to analyze changes that took place from 2011 to 2019 in the bibliographic information of 558 journals that applied for KOFST funding in 2011. Specifically, we first traced several pieces of bibliographic information in 2011 and 2019. Second, we performed a comparative analysis of the data from those years; and third, we conducted a comparative analysis by research field. The results should inform future strategies for the promotion of Korean academic journals with regard to bibliographic information.

\section{Methods}

Ethics statement: Because this was a literature-based study, neither institutional review board approval nor informed consent was required.

Study design: This study was a literature-based descriptive and comparative study of the bibliographic information associated with Korean journals over 8 years of follow-up.

Data sources: Scientific journals that applied for KOFST funding in 2011 were included and examined and were analyzed again in 2019. In 2011, the number of target journals was 558. However, 14 journals were discontinued or consolidated with other journals during the study period; therefore, the final number of journals analyzed was 544 .

Measurement: Between May and October 2012, PDF files of one issues and journal homepages of 558 journals were examined with respect to certain bibliographic information. The publishers confirmed the results of this examination. Those 558 journals were traced in August 2019 regarding the presence of the same information. The following bibliographic information was gathered: 1) journal title, 2) publisher name, 3) print International Standard Serial Number (pISSN), 4) electronic International Standard Serial Number (eISSN), 5) digital object identifier (DOI) prefix, 6) journal homepage URL, 7) "aims and scope" description, 8) frequency, 9) language, 10) existence of an open access policy, 11) research field, 12) title change, and 13) indexing in the Science Citation Index Expanded (SCIE).

The language of the journal was determined to be English if the full texts of all articles were written in English. Otherwise, it was categorized as Korean or Korean/English. Even issues containing English full-text articles were counted as Korean/English as long as at least one article was written in Korean. The existence of an open access policy was determined by evaluating the presence of an open access statement, including Creative Commons license information, in the masthead or the article. Statistical methods: The data were described without further statistical analysis, because this study was an analysis of all target journals that applied for financial support from KOFST.

\section{Results}

Descriptive data: Raw data are available in Dataset 1. Table 1 shows the status of 544 journals traced 8 years later, after excluding 14 journals that had been discontinued or consolidated. In total, 121 of the 544 journals (22.2\%) underwent title changes during the study period. Coded data for comparison was in Dataset 2.

A total of 544 journals were compared, excluding 14 journal titles discontinued prior to 2019. The number of journals according to research field was as follows: agriculture and fisheries, 65; engineering, 195; medicine, 191; and natural science, 93. With regard to frequency, quarterly (235) and bimonthly (180) publication schedules were most common in 2011. This trend was the same in 2019 (quarterly, 230; bimonthly, 195) (Fig. 1). The number of journals with pISSNs decreased from 541 (99.4\%) in 2011 to 488 (89.7\%) in 2019. In contrast, the number of journals with eISSNs increased from 214 (39.3\%) in 2011 to 488 (89.7\%) in 2019 (Fig. 2). "Aims and scope" descriptions were found in 291 (53.5\%) and 482 (88.6\%) journals in 2011 and 2019, respectively. The number of English-only journals increased from 163 (30.0\%) to 227 (41.7\%) over the study period. In 2011, 92 journals (16.9\%) had an open access policy, while this number was 315 (57.9\%) in 2019 (Fig. 3). The number of SCIE journals was 87 (16.0\%) in 2011 and 108 (19.9\%) in 2019.

Between 2011 and 2019, the number of English-only journals changed from 15 to 23 in the field of agriculture and fisheries, from 43 to 50 in engineering, from 64 to 110 in medicine, and from 41 to 44 in natural sciences (Fig. 4). During that same period, the number of open access journals changed from 10 to 32 in agriculture and fisheries, from 29 to 79 in en- 
Table 1. Bibliographic information of the 544 Korean scientific journals in 2011 and 2019

\begin{tabular}{llcc}
\hline Item & \multicolumn{1}{c}{ Classification } & 2011 & 2019 \\
\hline Language & Korean, Korean/English & $381(70.0)$ & $317(58.3)$ \\
& English & $163(30.0)$ & $227(41.7)$ \\
pISSN & Yes & $541(99.4)$ & $519(95.4)$ \\
& No & $3(0.6)$ & $25(4.6)$ \\
eISSN & Yes & $214(39.3)$ & $488(89.7)$ \\
DOI & No & $330(60.7)$ & $56(10.3)$ \\
& Yes & $256(47.1)$ & $534(98.2)$ \\
Open access statement & Yes & $288(52.9)$ & $10(1.8)$ \\
& No & $92(16.9)$ & $315(57.9)$ \\
Aims and scope & Yes & $452(83.1)$ & $229(42.1)$ \\
description & No & $291(53.5)$ & $482(88.6)$ \\
Frequency & Monthly & $253(46.5)$ & $62(11.4)$ \\
& Bimonthly & $58(10.7)$ & $67(12.3)$ \\
& Quarterly & $180(33.1)$ & $195(35.8)$ \\
& Three times a year & $235(43.2)$ & $230(42.3)$ \\
& Semiannually & $25(4.6)$ & $12(2.2)$ \\
& Others & $19(3.5)$ & $25(4.6)$ \\
\hline
\end{tabular}

pISSN, print International Standard Serial Number; elSSN, electronic International Standard Serial Number; DOI, digital object identifier.

gineering, from 31 to 161 in medicine, and from 22 to 43 in natural science (Fig. 5). In 2011, there were three online-only journals with eISSNs, but without pISSNs: one in engineering and two in medicine. However, this number had increased to 24 by 2019 (agriculture and fisheries, 2; engineering, 4; medicine, 9; natural sciences, 9).

\section{Discussion}

Key results: At the time of the follow-up analysis, 14 journals of the 588 that were identified in 2011 had been discontinued. Over the same 8 years, 121 journals had changed titles. The number of journals with eISSNs, "aims and scope" descriptions, Englishonly status, open access policies, and DOI prefixes increased over the 8 years. The number of SCIE journals increased from 87 (16.0\%) in 2011 to 108 (19.9\%) in 2019.

Interpretation: The changes detailed above indicate that the editors and publishers have made great efforts to promote Korean journals to the international level, which means the fulfillment of the essential bibliographic information. The proportion of journals with DOI prefixes in 2019 was remarkable, at $98.2 \%$. DOIs were rapidly introduced to most journals after they became a prerequisite to financial support by KOFST [1]. Also constituting an increase, $89.7 \%$ of journals evaluated in 2019 had eISSNs, which is similarly a requirement for KOFST funding. Another noteworthy change was the title change of 121 journals, which is evidence of the effort to globalize these journals. In most cases, the word "Korean" was omitted from the journal titles. By eliminating local names from journal titles, editors show that they want to recruit manuscripts from all over the world. It is inevitable that some editors would desire to widen the scope of authors from which they recruit papers because the number of articles published in journals in Korea has decreased year over year [2]. According to the increased research and development budget in Korea, Korean scientists' research and writing competence have increased while the pressure to publish in SCIE journals persists. It is thus typical for the editors of local journals not to receive the highest-quality manuscripts.

Regarding the increase in English-only journals, this trend was especially prevalent in the medical field, and the reason for it is the same as that behind the journal title changes. In 2019, in medicine, the number of English-only journals was 110, while that of Korean or Korean/English journals was 81. This tendency toward English-only publications is based on the eligibility for listing in PubMed Central (PMC), which is a Journal Article Tag Suite XML-based full-text literature database maintained by the United States National Library of Medicine. To be listed in PMC, a journal must have Englishonly full texts of its articles. Journals from Korea began to be listed in PMC in 2018. By January 2020, 120 PMC-listed journals were Korean. Because PMC journals are searchable in PubMed, PMC eligibility became a strong incentive for medical journal editors in Korea to change the journal language to English-only. Open access is also more common in the medical field (161 of 191 journals [84.3\%]) than in other areas (less than $50 \%$ of journals). An open access declaration is similarly a prerequisite to $\mathrm{PMC}$ participation.

Although some journals in fields other than medicine lack explicit open access statements, they are usually available under free access. In this study, only journals with open access statements under the Creative Commons license were considered to be open access. However, 164 additional journals were freely accessible. Only 65 journals were closed-access or had no available homepage.

What is the main background of the above change in Korean scientific journals? The most critical incentive was the selection criteria by KOFST for journal support, where that bibliographic information was listed. Furthermore, there may be journal editors' efforts to upgrade the journal.

Limitation: Data in 2011 were obtained from PDFs of the print versions and the online versions of the journals, while data 

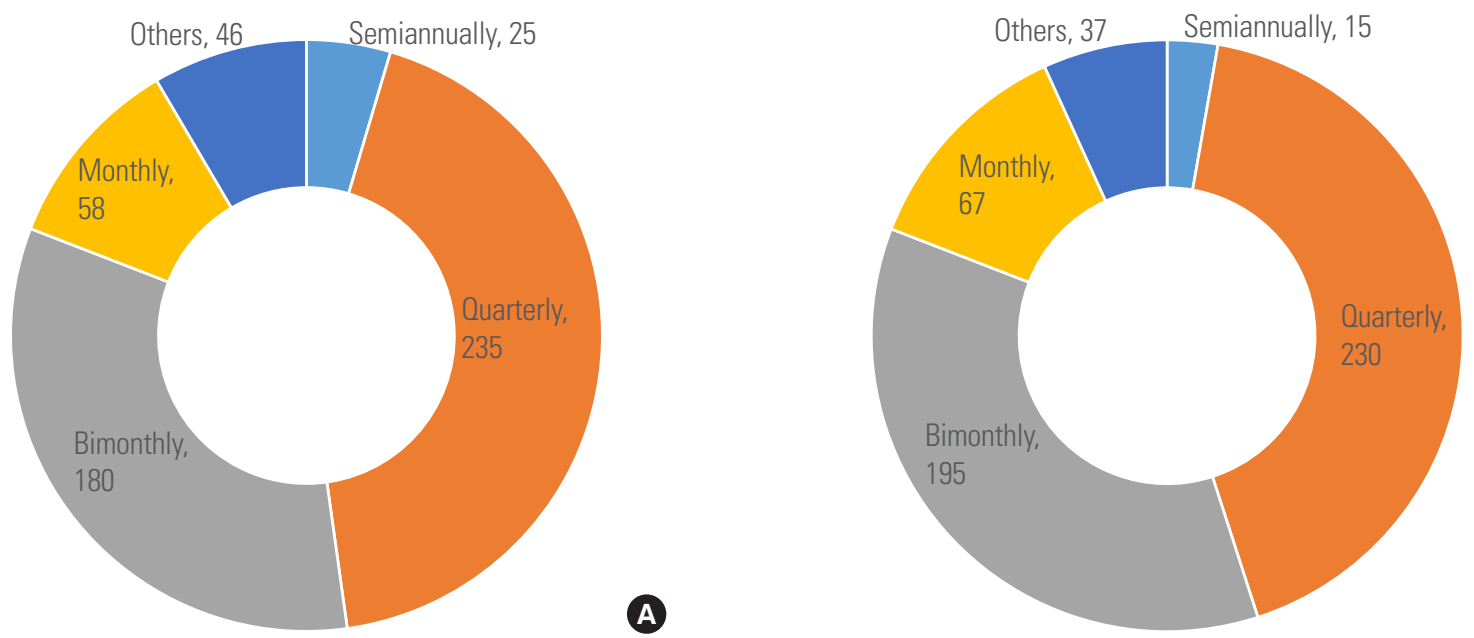

B

Fig. 1. Changes in the publication frequency of scientific journals in Korea from 2011 (A) to 2019 (B).

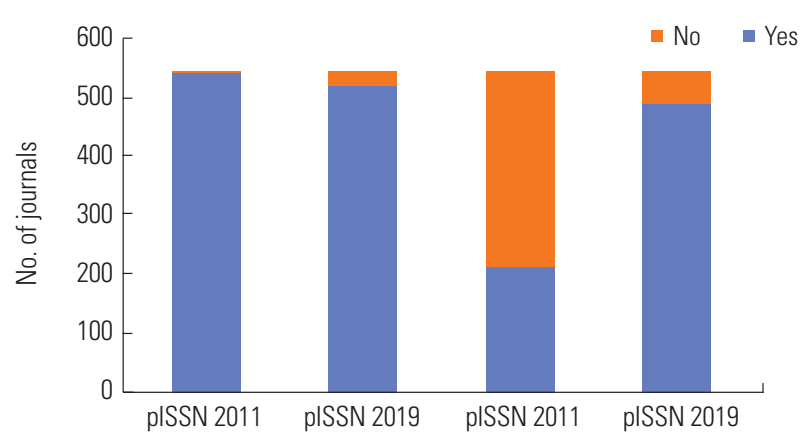

Fig. 2. Changes in International Standard Serial Number (ISSN) information of scientific journals in Korea from 2011 to 2019. pISSN, print ISSN; eISSN, electronic ISSN.

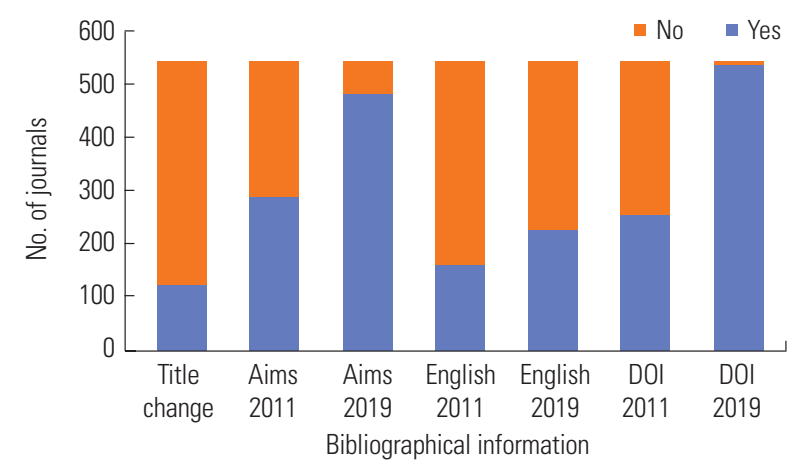

Fig. 3. Changes in bibliographic information (title, "aims and scope" description, language, DOI) of scientific journals in Korea from 2011 to 2019. DOI, digital object identifier.

obtained in 2019 came only from the journals' homepages. Therefore, we cannot rule out the possibility of incomplete information or error due to the careless maintenance of the online versions of journals by publishers. As for the 2019 data, only one author performed the search, and the publishers did

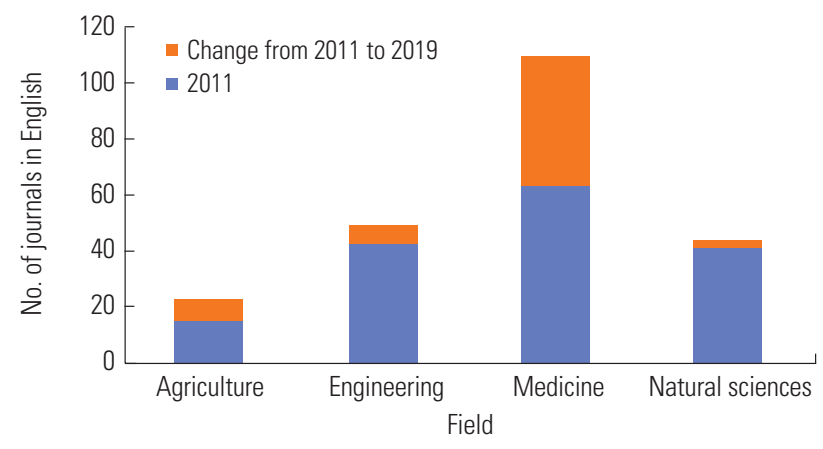

Fig. 4. Changes in the number of English-language scientific journals in Korea from 2011 to 2019 by research field.

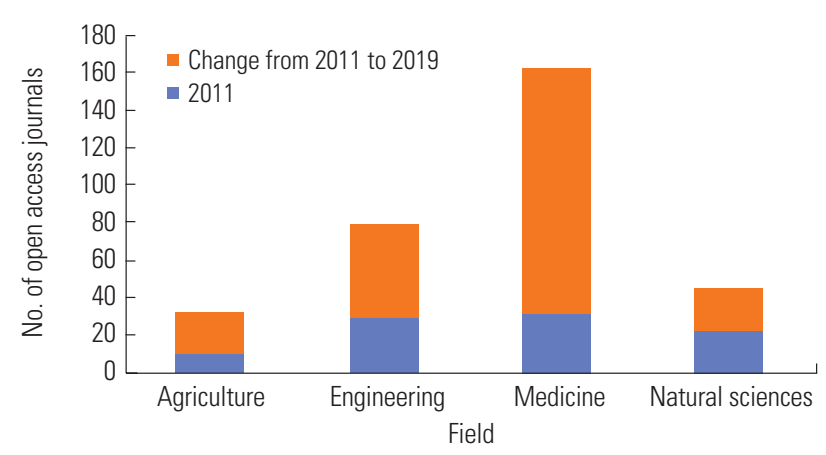

Fig. 5. Changes in the number of open access journals in Korea from 2011 to 2019 by research field.

not confirm the data or results. Unintentional errors, therefore, may have been present in the search for and recording of data in 2019. The target journals of this study were those that applied for KOFST funding in 2011; journals that did not apply were not included, nor were journals launched after 2011. 
Generalizability: The results of this study are representative of the status of scientific journals in Korea, as the number of scientific journals in the Korea Citation Index was 769 in December 2019. Although some journals published by commercial publishing companies or universities and public institutions do not apply for KOFST funding, most society journals do so.

Conclusion: Current bibliographic information has evolved considerably, and the standards for scholarly journals have been well established for 8 years. However, some journals still do not issue DOIs, do not display eISSNs on their websites, and do not disclose detailed descriptions of necessary bibliographic information online. For example, some journals still do not explicitly describe their aims and scope on their homepage. The data mentioned above ("aims and scope" description, DOI, eISSN, etc.) should be clearly marked on the website as necessary bibliographic information associated with the journal. The quickest way to clarify the essential bibliographic information was to evaluate a journal's compliance with the "Principles of transparency and best practice in scholarly publishing, 3rd version" [3]. All journals that apply for KOFST funding can attempt to follow these standards. In addition to the content of a journal, the appearance of the website should follow international standards.

\section{Conflict of Interest}

Sun Huh has been the President of the Korean Council of Science Editors since January 17, 2020. Hye-Min Cho serves as an editor of the Science Editing, but has no role in the decision to publish this article. Except for that, no potential conflict of interest relevant to this article was reported.

\section{Acknowledgments}

The work to obtain the bibliographic information of the journals from the last issue of 2011 was supported by the Korean Federation of Science and Technology Societies (2012), and the recipient of this financial support was Hye-Min Cho.

\section{Data Availability}

Dataset is available from the Harvard Dataverse at: https://doi. org/10.7910/DVN/DCAEC1.

Dataset 1. Raw data of 558 journals' bibliographic information in 2011 and 2019 Dataset 2. Coded data for comparison of the 544 journals' bibliographic information between in 2011 and in 2019

\section{References}

1. Jeong GH, Huh S. Analysis of the suitability of the Korean Federation of Science and Technology Societies journal evaluation tool. Learn Publ 2016;29:193-8. https://doi. org/10.1002/leap.1037

2. Huh S. Presidential address: how to cope with the present environment of scholarly journal publishing. Sci Ed 2020;7: 1-3. https://doi.org/10.6087/kcse.181

3. Choi HW, Choi YJ, Kim S. Compliance of "Principles of transparency and best practice in scholarly publishing" in academic society published journals. Sci Ed 2019;6:11221. https://doi.org/10.6087/kcse.171 